\title{
Photodegradation of Methyl Orange in Aqueous Solution by the Visible Light Active Co:La:TiO ${ }_{2}$ Nanocomposite
}

\section{Azad $K^{*}$ and Gajanan P}

Department of Applied Chemistry, School for Physical Sciences, Babasaheb Bhimrao Ambedkar University, Lucknow, Uttar Pradesh, India

\begin{abstract}
In this study, the Co:La: $\mathrm{TiO}_{2}$ nanocomposite was prepared by the wet chemical method. Synthesized $\mathrm{TiO}_{2}$ and Co:La:TiO ${ }_{2}$ were characterized by X-Ray Diffractometer, SEM, TEM, UV- vis, FT-IR, Band gap energy and BET. The $\mathrm{TiO}_{2}$ and $\mathrm{Co}: \mathrm{La}: \mathrm{TiO}_{2}$ were used as photocatalyst for the degradation of Methyl Blue. The XRD pattern confirmed the presence of anatase and rutile phase in the catalyst. The particle size was estimated by the Scherrer's and found 68 and $32 \mathrm{~nm}$ for $\mathrm{TiO}_{2}$ and $\mathrm{Co}: \mathrm{La}: \mathrm{TiO}_{2}$ respectively. The particle morphology of the photocatalysts was found in nanodiamension. The surface area of the photocatalysts was found 37.52 and $106.68 \mathrm{~m}^{2} / \mathrm{g}$ for TiO ${ }_{2}$ and Co:La: $\mathrm{TiO}_{2}$ respectively. The band gap energy of $\mathrm{TiO}_{2}$ and $\mathrm{Co}: \mathrm{La}: \mathrm{TiO}_{2}$ were 3.2 and $3.0 \mathrm{eV}$. The photodegradation of Methyl Orange has been found $18 \%$ and $88 \%$ at $5 \mathrm{pH}$ for $\mathrm{TiO}_{2}$ and $\mathrm{Co}: \mathrm{La}^{\mathrm{TiO}}$ respectively. The photodegradation of Methyl Orange has been found $19 \%$ and $98.9 \%$ at $25 \mathrm{ppm}$ concentration of dye. The photodegradation of Methyl Orange has been found $25 \%$ and $96 \%$ at $800 \mathrm{mg} / \mathrm{L}$ amount of photocatalyst and 180 min illumination of visible light. The photodegradation was following the first order kinetics.
\end{abstract}

Keywords: Photodegradation; Photocatalyst; Photocatalysis; Methyl orange; Nanocomposite

\section{Introduction}

Dyes are not safe aggravates that are found in modern waste water bringing about unfriendly natural issues. A large portion of the dyes utilized as a part of the pigmentation of materials, leather, paper, ceramic production, and nourishment handling are found from azo dyes. Dyes are lost with waste water in the midst of preparing [1-5]. This speaks to a tremendous danger to human and ecological wellbeing because of the poisonous quality of azo dyes [6]. The treatment of such defilements can be proficient by heterogeneous photocatalysis in light of its capability and negligible exertion and furthermore to the way that it grants complete poisonous quality of dyes to carbon dioxide and inorganic acids [7-9].

Titanium dioxide $\mathrm{TiO}_{2}$ is a most vital nanomaterial's which has pulled in an awesome consideration because of its novel properties. Titanium dioxide $\mathrm{TiO}_{2}$ have great merits in solar powered vitality exchanging and photocatalysis of toxic substance in environmental condition. The concoction inactivity and the non-poisonous quality of $\mathrm{TiO}_{2}$ have likewise made it a predominant photocatalyst [10-13]. Titania has a substantial band hole $\left(3.20 \mathrm{eV}\right.$ for anatase $\left.\mathrm{TiO}_{2}\right)$ and along these lines, just a little part of sunlight based light can be absorbed [14]. Many endeavours have been made to sensitized titanium dioxide to the entire visible range, for example, doping with d block metals $[15,16]$, d block metal ions [17], non-metal atoms [18] and organic materials [19]. An acquaintance of dopant permits Titania with assimilating in the visible region yet this does not really imply that the doped photocatalyst has a superior photocatalytic activity. In photocatalysis, light is consumed by an adsorbed substrate. Today, semiconductors are generally chosen as photocatalysts, on the grounds that semiconductors have a narrow band gap between the valence and conduction groups [20]. With the end goal for photocatalysis to continue, the semiconductors need to assimilated vitality equivalent to or more than its vitality crevice. When $\mathrm{TiO}_{2}$ is irradiated by UV light (400 nm or less), electron is excited to generate electron $\left(\mathrm{e}^{-}\right)$hole $\left(\mathrm{h}^{+}\right)$pairs [21]. This movement of electrons forms $\mathrm{e}^{\mathrm{e}} / \mathrm{h}^{+}$or negatively charged electron/positively charged hole pairs. The hole can oxidize donor molecules. In photogenerated catalysis the photocatalytic activity (PCA) depends on the ability of the catalyst to create electron-hole pairs, which generate free radicals able to undergo secondary reactions [22-24].

In this study, the nanocomposites of Cobalt, Lanthanum and Titania were prepared. The prepared nanocomposites used for the photodegradation of methyl orange at different parameters i.e., $\mathrm{pH}$ of solution, temperature of reaction, concentration of dye, amount of photocatalyst and irradiation time. The Kinetic and thermodynamic parameters were determined for the photodegradation of methyl orange.

\section{Methodology}

\section{Synthesis of Titania by wet chemical method}

In this method, both $\mathrm{TiCl}_{4}$ solution $(1000 \mathrm{mg} / \mathrm{l})$ and $\mathrm{NaOH}$ solution $(64.5 \mathrm{~g} / \mathrm{l})$ was added drop wise to water with stirring. After the resulting solution reaches $\mathrm{pH}$ to 7 , the slurry was filtered, and the filter cake of $\mathrm{TiO}_{2}$ was washed and redispersed in water to prepare $1 \mathrm{M}$ of $\mathrm{TiO}_{2}$ slurry. Resulting $\mathrm{TiO}_{2}$ slurry and an aqueous solution of $\mathrm{HNO}_{3}$ were refluxed at $95^{\circ} \mathrm{C}$ for $2 \mathrm{~h}$, cooled to room temperature and neutralized with $28 \%$ of aqueous ammonia. Then, it was filtered, washed and calcined at $400^{\circ} \mathrm{C}[25,26]$.

$$
\begin{array}{ll}
\mathrm{TiCl}_{4}+4 \mathrm{NaOH} & \rightarrow \mathrm{Ti}(\mathrm{OH})_{4}+4 \mathrm{NaCl} \\
\mathrm{Ti}(\mathrm{OH})_{4} & \rightarrow \mathrm{TiO}_{2}+2 \mathrm{H}_{2} \mathrm{O}
\end{array}
$$

\section{Synthesis of Co:La: $\mathrm{TiO}_{2}$ nanocomposite}

In this study, $\mathrm{Co}: \mathrm{La}_{\mathrm{TiO}} \mathrm{Ti}_{2}$ nanocomposites were prepared by solution

*Corresponding authors: Azad K, Department of Applied Chemistry, School for Physical Sciences, Babasaheb Bhimrao Ambedkar University, Lucknow-226 025, India, Tel: +917785881643; E-mail: kumarazad20@gmail.com

Received July 12, 2017; Accepted July 17, 2017; Published August 13, 2017

Citation: Azad K, Gajanan P (2017) Photodegradation of Methyl Orange in Aqueous Solution by the Visible Light Active Co:La:TiO Nanocomposite. Chem Sci J 8: 164. doi: 10.4172/2150-3494.1000164

Copyright: ( 2017 Azad K, et al. This is an open-access article distributed under the terms of the Creative Commons Attribution License, which permits unrestricted use, distribution, and reproduction in any medium, provided the original author and source are credited. 
Citation: Azad K, Gajanan P (2017) Photodegradation of Methyl Orange in Aqueous Solution by the Visible Light Active Co:La:TiO ${ }_{2}$ Nanocomposite. Chem Sci J 8: 164. doi: 10.4172/2150-3494.1000164

impregnation method. In this method suitable quantity of prepared $\mathrm{TiO}_{2}(2 \mathrm{~g})$ was dispersed in alcoholic cobalt acetate $10 \%(\mathrm{w} / \mathrm{v})$ and lanthanum nitrate $5 \%(\mathrm{w} / \mathrm{v})$. The dispersion is agitated continuously for 4 hour at $100^{\circ} \mathrm{C}$ temperature. After the treatment the residue was removed through filtration and was sintered for 4 hour in presence of air at $600^{\circ} \mathrm{C}$ by kipping it in a silica crucible inside the muffle furnace. After sintering and slow anilling to room temperature, content was taken out from furnace and was stored in air tight bottles and was used as photocatalyst [27].

$$
\mathrm{TiO}_{2}+\mathrm{Co}\left(\mathrm{CH}_{3} \mathrm{COO}\right)_{2}+\mathrm{La}\left(\mathrm{NO}_{3}\right)_{3} \rightarrow \mathrm{Co}: \mathrm{La}: \mathrm{TiO}_{2}
$$

\section{Characterization}

The prepared samples were subjected to $\mathrm{x}$-ray diffraction analysis on Powder X-Ray Diffractometer. The observed X-Ray diffractogram of samples were analyzed further to estimate average grain size in the sample by Scherrer's calculation. Since the absorption of light by photocatalyst is the most crucial step in any photocatalysed reaction, and is decided primarily by the band gap energy of catalyst. The morphology and size of the Titania particles were determined by transmission electron microscopy (TEM) and scanning electron microscopy (SEM).

\section{Results}

\section{Phase identification by $\mathrm{X}$-Ray diffraction analysis}

The obtained X-Ray diffraction patterns of Titania and Co:La:TiO are shown in Figures 1a and 1b. The observed pattern of peaks, when compared with the standard JCPDS database, suggested that, in prepared $\mathrm{TiO}_{2}$ sample, major peaks at $2 \theta=25.5^{\circ} 37.2,48.3$, and 54.5 , which can be indexed to the (101), (004), (200), and (211) facet of anatase $\mathrm{TiO}_{2}$. While major peaks at $2 \theta=26.9^{\circ}$ and $28.2^{\circ}$ demonstrate the presence of rutile phase which can be indexed to the (110), (121), individually. In case of Co: $\mathrm{La}: \mathrm{TiO}_{2}$ sample, the observed XRD pattern indicates not only a change in the peak intensity, compared to $\mathrm{TiO}_{2}$, but even the absence of some originally observed $\mathrm{TiO}_{2}$ peaks [28]. This is, probably, due to the change in the crystallinity and grain fragmentation, when the samples were wet impregnated by cobalt and Lanthanum.

Determination of average size of crystal in samples: The Scherrer's calculations were attempted to know the average size of crystal in the samples [28]. Although, Scherrer's calculations are only approximate in nature, but definitely provide a first-hand idea of the average size of the crystal in the samples, which may be quite accurate, provided the size of crystal is below $100 \mathrm{~nm}$. The results of Scherrer's calculations are presented in Table 1. The crystal size was found in the nm range.

\section{Scanning Electron Microscopy (SEM)}

The morphology of the samples was investigated by scanning
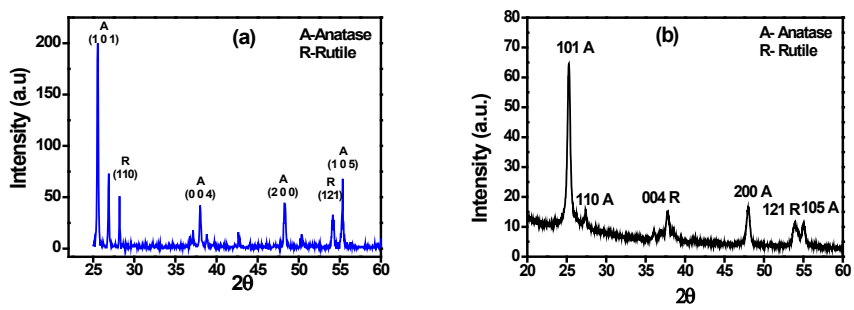

Figure 1: Observed XRD pattern $(\mathrm{A}) \mathrm{TiO}_{2}(\mathrm{~B}) \mathrm{Co}: \mathrm{La}: \mathrm{TiO}_{2}$. electron microscopy and it resumes the most interesting outcomes. Figure 2 clearly show that both the prepared samples are obtained in nanometric dimension. The size of Co:La:TiO ${ }_{2}$ was $160 \mathrm{~nm}$ whereas $200 \mathrm{~nm}$ for $\mathrm{TiO}_{2}$. This is due to the impregnation of metal ions in Titania [29].

\section{Transmission Electron Microscope (TEM)}

TEM images were clearly displayed the morphology and particle size of neat $\mathrm{TiO}_{2}$ and Cobalt and lanthanum doped $\mathrm{TiO}_{2}$. From the Figure 3 we find that Cobalt and lanthanum doped modified $\mathrm{TiO}_{2}$ change the size of neat $\mathrm{TiO}_{2}$ significantly, as shown in Figure $3 \mathrm{a}$ and $3 \mathrm{~b}$. The sizes of both modified and neat $\mathrm{TiO}_{2}$ are mono disperse about 100 $200 \mathrm{~nm}$. Moreover, the crystal lattice line can be clearly found in the TEM images. The aggregations of both kinds of particles are caused by high surface energy; however, the agglomeration of the modified one is alleviated obviously compared with that of the neat [30].

\section{Surface area analysis (BET)}

Figure 4 demonstrated the BET and adsorption and desorption plot for the $\mathrm{TiO}_{2}$ and $\mathrm{Co}: \mathrm{La}: \mathrm{TiO}_{2}$. Figure 4 showed adsorption-desorption of nitrogen and with the help of nitrogen adsorption to determine the surface area, pore volume and average pore size of the $\mathrm{TiO}_{2}$ and Co:La:TiO 2 photocatalyst. The surface parameters of $\mathrm{TiO}_{2}$ and Co:La: $\mathrm{TiO}_{2}$ was shown in Table 2. The $\mathrm{TiO}_{2}$ modified by Cobalt and Lanthanum are fragmentation to some extent during heat treatment,

\begin{tabular}{|c|c|}
\hline Sample & Crystal Size \\
\hline $\mathrm{TiO}_{2}$ & 68 \\
\hline $\mathrm{Co}: \mathrm{La}_{\mathrm{TiO}}$ & 32 \\
\hline
\end{tabular}

Table 1: Average size of crystal in the samples of $\mathrm{TiO}_{2}$ and Co:La: $\mathrm{TiO}_{2}$.

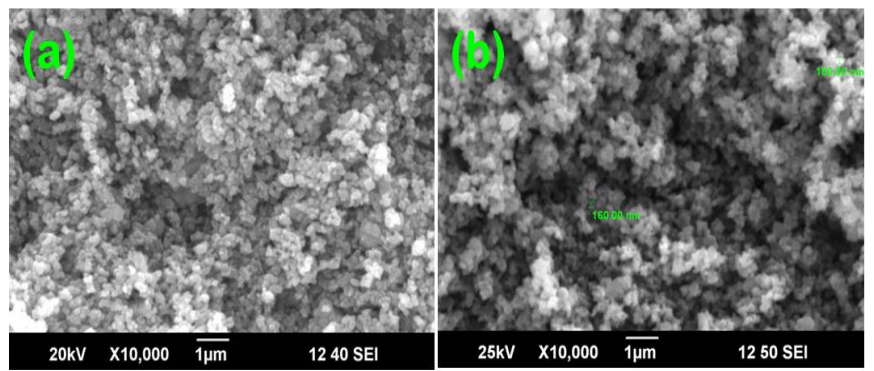

Figure 2: SEM image of the (A) $\mathrm{TiO}_{2}(\mathrm{~B}) \mathrm{Co}: \mathrm{La}: \mathrm{TiO}_{2}$
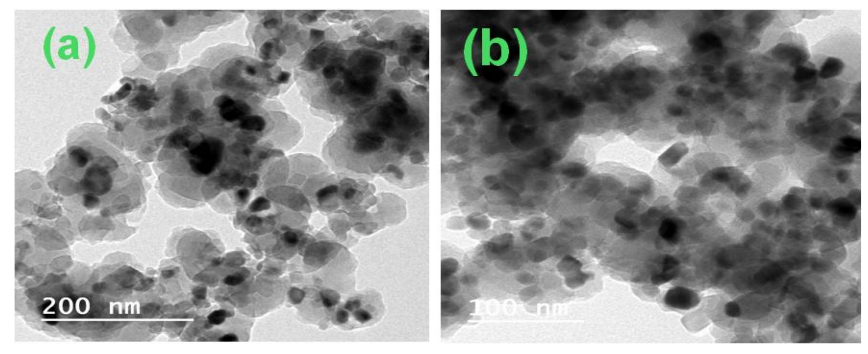

Figure 3: TEM image of the (a) $\mathrm{TiO}_{2}$ (b) Co:La: $\mathrm{TiO}_{2}$.

\begin{tabular}{|c|c|c|c|}
\hline Sample & Surface area $\left(\mathrm{m}^{2} / \mathrm{g}\right)$ & Pore volume $\left(\mathrm{cm}^{3} / \mathrm{g}\right)$ & Pore radius $(\mathrm{nm})$ \\
\hline $\mathrm{TiO} 2$ & 37.52 & 10.132 & 1.21 \\
\hline Co:La: $\mathrm{TiO}_{2}$ & 106.68 & 9.5124 & 1.64 \\
\hline
\end{tabular}

Table 2: The specific surface area, pore volume and pore radius of the $\mathrm{TiO}_{2}$ and Co:La:TiO . 

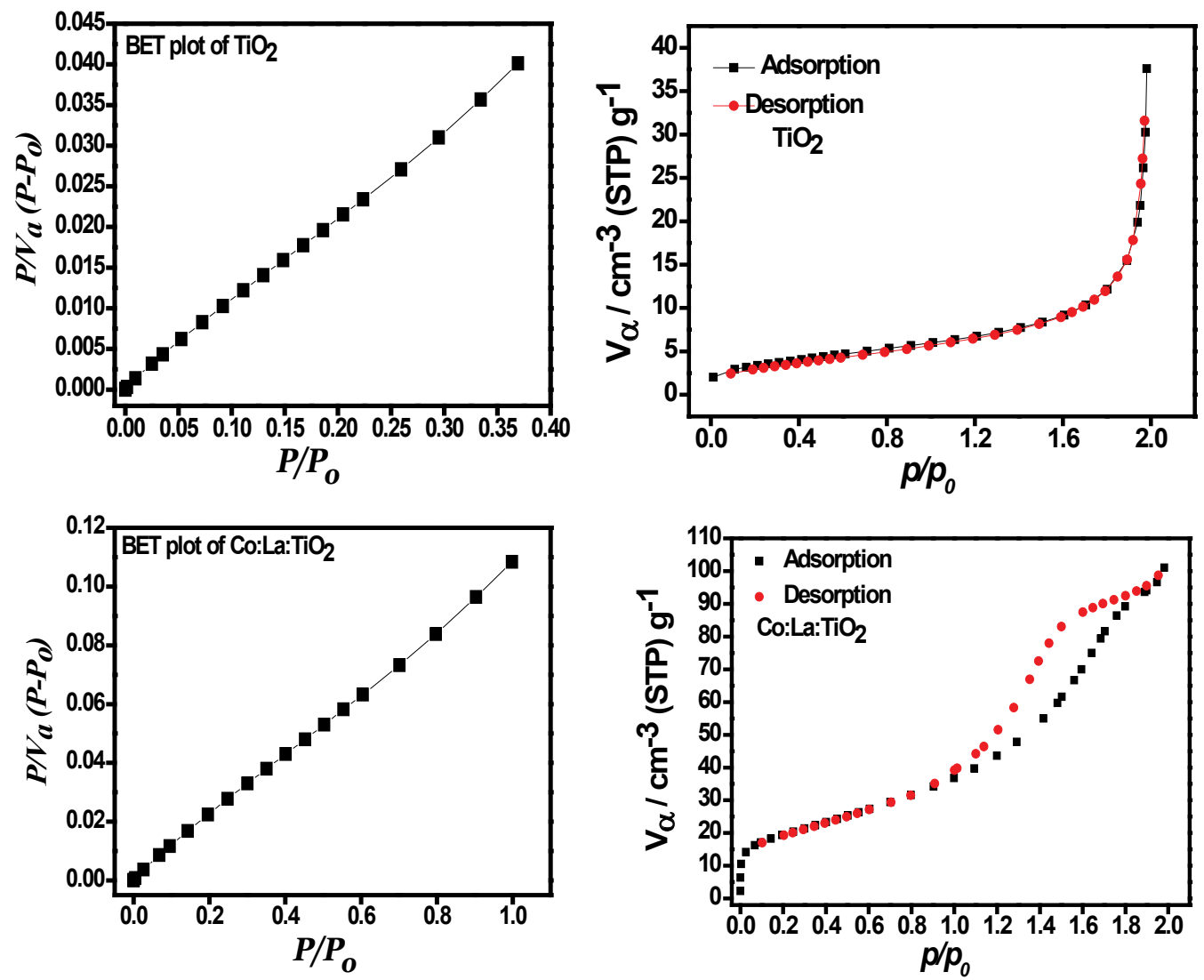

Figure 4: BET and Adsorption desorption plot for $\mathrm{TiO}_{2}$ and $\mathrm{Co}: \mathrm{La}: \mathrm{TiO}_{2}$.

leading to a marked increment of the BET surface areas and the average pore radius size and diminishing of the pore volume [31,32].

\section{Band gap energy determination}

The band gap of samples was calculated by extrapolation of the $(\alpha h v)^{2}$ versus $h v$ plots, where $\alpha$ is the absorption coefficient and $h v$ is the photon energy, $h v=(1239 / \lambda) \mathrm{eV}$. The value of $h v$ extrapolated to $\alpha=0$ gives an absorption energy, which corresponds to a band gap ( $E \mathrm{~g})$. Figure 5 yields an $E g$ value of $3.2 \mathrm{eV}$ for $\mathrm{TiO}_{2}$ and 3.0 for Co: $\mathrm{La}_{\mathrm{TiO}}$ [33]. The slight decrease in band gap energy in case of Co:La:TiO, is due to formation of sub-band level between valence band and conduction band caused impregnation of $\mathrm{Co}^{+2}$ and $\mathrm{La}^{+3}$ in $\mathrm{TiO}_{2}$ host.

\section{Adsorption study}

A control experiment was first carried out under two conditions, vis (i) dye $+\mathrm{UV}\left(\right.$ no $\mathrm{TiO}_{2}$ ) (ii) $\mathrm{TiO}_{2}+$ dye in dark without any irradiation (Figure 6). It can be seen that under dark conditions, after $20 \mathrm{~min}$ the amount of catalyst adsorbed becomes constant i.e., equilibrium adsorption is achieved. The reaction of methyl orange in presence of $\mathrm{TiO}_{2}$ and $\mathrm{Co}: \mathrm{La}: \mathrm{TiO}_{2}$ nanocomposites and UV irradiation is an example of heterogeneous catalysis. Rate laws in such reactions seldom follow proper law models and hence are inherently more difficult to formulate from the data. It has been widely accepted that heterogeneous catalytic reactions can be analyzed with the help of Langmuir Hinshelwood ( $\mathrm{LH})$ Model $[34,35]$, with the following assumptions being satisfied, (i) there are limited number of adsorption sites on the catalyst and its surface is homogeneous, (ii) only one molecule can be adsorbed on one site and
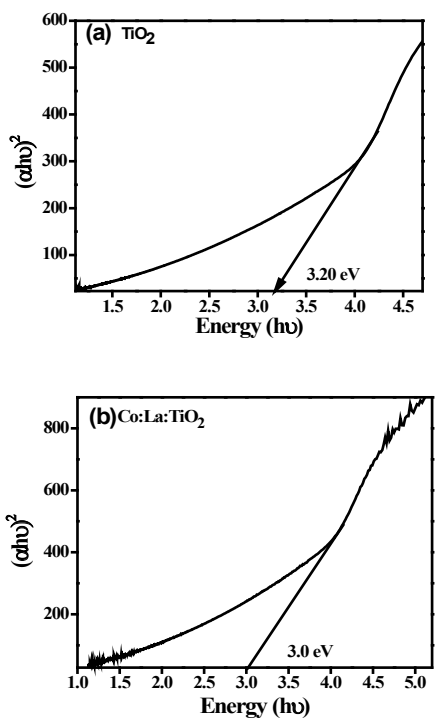

Figure 5: Band gap energy of (a) $\mathrm{TiO}_{2}$ (b) $\mathrm{Co}: \mathrm{La}: \mathrm{TiO}_{2}$.

monolayer formation occurs (iii) the absorption reaction is reversible in nature, and (iv) The adsorbed molecules do not react amongst themselves [36-38]. According to LH Model, following steps take place in the kinetics mechanism [39-43] (Adsorption of dye onto the catalyst surface). There are three steps of adsorption, Surface reaction, 

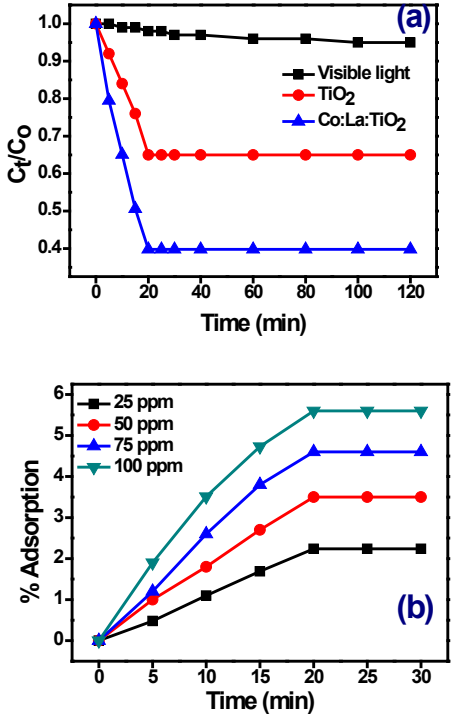

Figure 6: (a) Change in concentration under dark with $\mathrm{TiO}_{2}, \mathrm{Co}: \mathrm{La}_{\mathrm{TiO}}$ and in UV light (b) under dark with $\mathrm{Co}: \mathrm{La}^{\mathrm{TiO}}{ }_{2}$ at different concentrations.

Desorption of products from the surface.

Step 1:- D (Dye)+C (catalyst) $\leftrightarrow$ D.C

Step 2:- D.C $\leftrightarrow$ E.C+ Other products

Step 3:- E.C $\leftrightarrow$ E+C

\section{Photo-degradation of dyes}

The photodegradation of Methyl Orange has been studied in the presence of $\mathrm{TiO}_{2}$ and $\mathrm{Co}: \mathrm{La}: \mathrm{TiO}_{2}$. The dye solution prepared in water and alcohol 10:1 (V/V) ratio. The definite amount $(100-800 \mathrm{mg} / \mathrm{L})$ of photocatalyst was dispersed in the dye solution. The dispersion was irradiated under visible light, although kept under agitation. After different time interval and different temperature the photocatalyst was separated from dispersion. The remaining concentration of dye in the dispersion mixture was determined spectrophotometrically. The photodegradation of Methyl Orange is showing in Figures 7-9.

Effect of temperature: The affected the temperature on photocatalysis reaction has not concerned enough interest. However, in this research, photodegradation of Methyl Orange has a vast effect of temperature. The photodegradation efficiency can be increased about 2-3 times if the temperature increased from $30^{\circ} \mathrm{C}$ to $40^{\circ} \mathrm{C}$ Because the solar energy include UV light, which can be used to activate the photocatalytic course, which is increase the temperature of photocatalytic system. The experiments showed that Methyl Orange were photodegraded in presence of photocatalyst and Visible light. The Methyl Orange was efficiently degraded shown in Figure 7. In presence of the $\mathrm{Co}: \mathrm{La}_{\mathrm{TiO}} \mathrm{Ti}_{2}$ at $40^{\circ} \mathrm{C}, 88 \%$ photodegradation was observed and $30^{\circ} \mathrm{C} 76 \%$ photodegradation observed. The obvious decrease of concentration of dye shows that the $\mathrm{Co}: \mathrm{La}_{\mathrm{TiO}}$ can serve as an effective photocatalyst as compared with pure $\mathrm{TiO}_{2}$ but in the blank experiment only $0.2 \%$ photodegradation observed due to the light radiation which causes the thermal action on the dye [44]. Co and La ions have low band gap energy than the pure Titania. Therefore the band gap energy of $\mathrm{Co}: \mathrm{La}_{\mathrm{TiO}}$, was reduce and capable to absorb the visible light radiation.

Effect of concentration of dye: The effect of concentration (from $25 \mathrm{ppm}$ to $100 \mathrm{ppm}$ ) of dye was studied on the photodegradation of

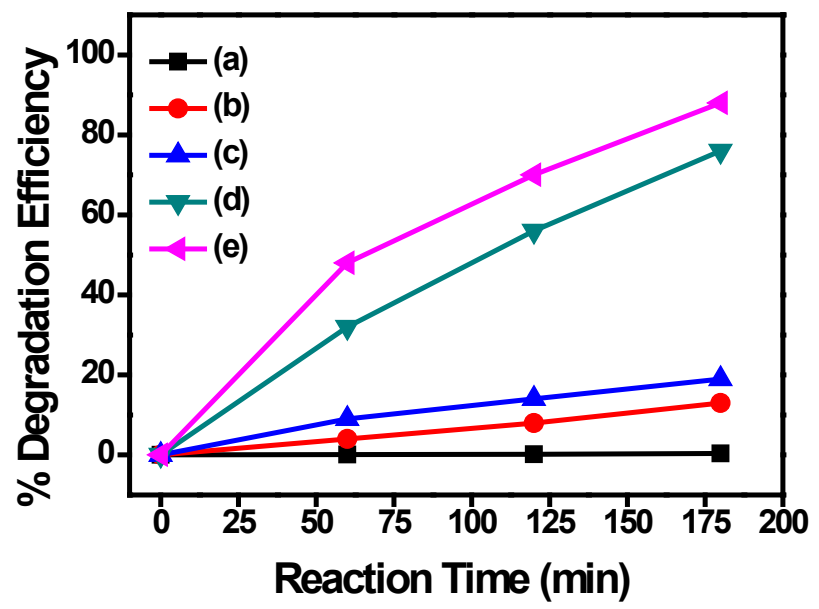

Figure 7: \% degradation of Methyl Orange with initial concentration $50 \mathrm{ppm}$ (a) without photocatalyst (b) $\mathrm{TiO}_{2}$ at $30^{\circ} \mathrm{C} \mathrm{(c)} \mathrm{TiO}_{2}$ at $40^{\circ} \mathrm{C} \mathrm{(d)} \mathrm{Co}: \mathrm{La}^{\circ} \mathrm{TiO}_{2}$ at $30^{\circ} \mathrm{C}$ (e) Co: $\mathrm{La}^{\mathrm{TiO}}{ }_{2}$ at $40^{\circ} \mathrm{C}$.

dye. The photodegradation of methyl orange is given in Figure 8a. the photodegradation of methyl orange were found maximum $19 \%$ and $98.9 \%$ at 25 ppm concentration, for $\mathrm{TiO}_{2}$ and $\mathrm{Co}: \mathrm{La}: \mathrm{TiO}_{2}$ respectively. The rate of photodegradation of Methyl Orange was found to decrease with the gradual increase in concentration. This is due to the hindrance created in the path of light by the number of dye molecules, therefore the number of photons penetrating in the dye solution is reduced, and hence catalyst surface is not received complete photons. Thus the formation of the reactive ${ }^{\otimes} \mathrm{OH}$ and $\mathrm{O}_{2}^{-}$radicals is reduced. Thus the optimum concentration of dye should be maintained in the photocatalytic reaction, where maximum efficiency of photodegradation can be found [45].

Effect of time on photocatalytic degradation of dye: In presence of $\mathrm{TiO}_{2}$ and $\mathrm{Co}: \mathrm{La}: \mathrm{TiO}_{2}$, the photodegradation of methyl Orange has been studied at different irradiation time. The photocatalytic degradation of methyl Orange was increased with increase of irradiation time. In case of Co:La: $\mathrm{TiO}_{2}$, The photodegradation was found $98 \%$ at 180 min irradiation of visible light but in case of pure titania only $18 \%$ photodegradation was observed. In case of blank experiment, there was no major change observed. The effect of irradiation time on photodegradation of methyl Orange is showing in Figure 8b. This is because of the dye molecule interaction with the surface of photocatalyst and the time of illumination increases, the interaction increased. Consequently the photodegradation efficiency of photocatalyst was increased [46].

Effect of $\mathbf{p H}$ of solution: The effect of $\mathrm{pH}$ (from 2 to 9) on photodegradation of methyl orange was determined. The $\mathrm{pH}$ of the solution was adjusting with $\mathrm{H}_{2} \mathrm{SO}_{4}$ and $\mathrm{NaOH}$, while kept at constant amounts of photocatalyst $800 \mathrm{mg} / \mathrm{L}$ and concentration of dye solutions (Figure $8 \mathrm{c}$ ). The observed photodegradation was found low photodegradation rates at acidic ranges of $\mathrm{pH}$. Although at $\mathrm{pH}$ 5 photodegradation was found maximum. This informed that less acidic situation are favourable towards the construction of the reactive intermediates that is hydroxyl radicals is extensively improved, which further help in enhancing the reaction rate. Alternatively in highly acidic conditions for the creation of reactive intermediates is comparatively less favourable and hence less spontaneous $[47,48]$.

Effect of photocatalyst amount: The effect of photocatalyst amount has been studied by applying the different amount (100 ppm 

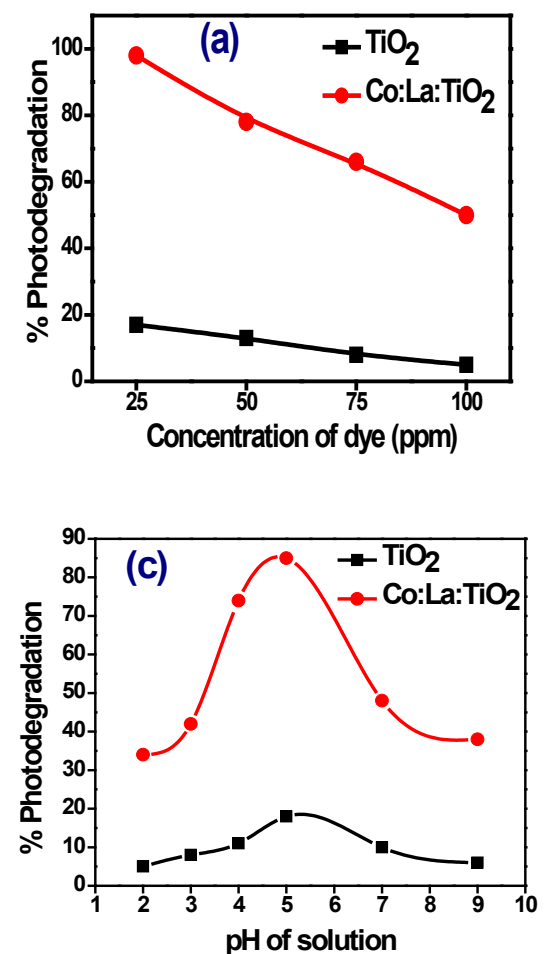
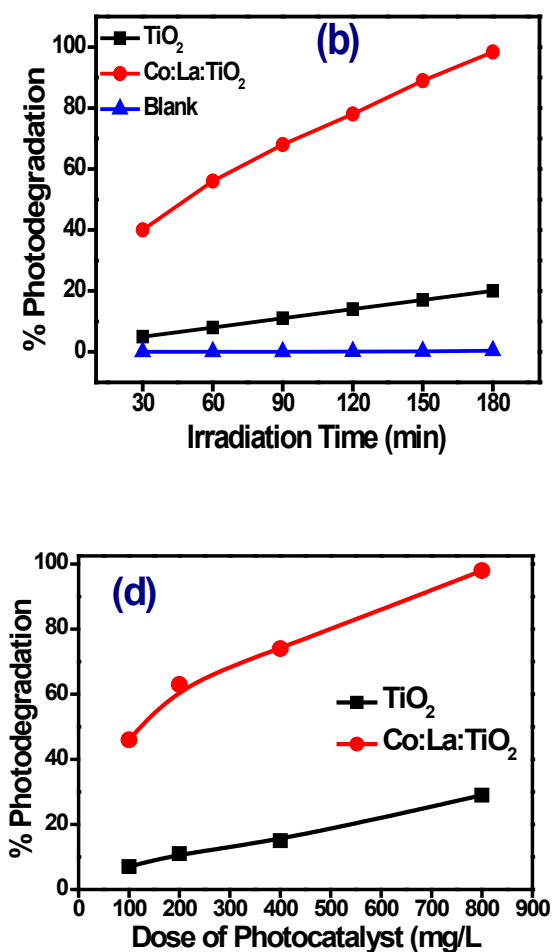

Figure 8: Photodegradation of Methyl Orange by recyclable photocatalyst $\mathrm{TiO}_{2}$ and Co:La: $\mathrm{TiO}_{2}$.

to $800 \mathrm{ppm}$ ) of the photocatalyst. The photodegradation rate was found to increase by increasing the amount of photocatalyst. It is clear from the results shown in Figure 8d, the photodegradation increased rapidly with increase of amount of $\mathrm{Co}: \mathrm{La}_{\mathrm{TiO}}$. This is due to the fact that introduction of $\mathrm{Co}^{2+}$ and $\mathrm{La}^{3+}$ into $\mathrm{TiO}_{2}$ the band gap energy decreased up to $3.0 \mathrm{eV}$ which enhance the photocatalytic activity [49].

Effect of photocatalyst: It is clear from the results shown in Figure 8 that both $\mathrm{TiO}_{2}$ and $\mathrm{Co}: \mathrm{La}: \mathrm{TiO}_{2}$ are efficient photocatalyst for the photodegradation of Methyl Orange dye. Though Co:La:TiO ${ }_{2}$ shows the good photocatalytic activity than pure $\mathrm{TiO}_{2}$ for the degradation of Methyl Orange dye. The major photodegradation of methyl orange was observed in 3 hour irradiation time, in the presence of Co:La:TiO ${ }_{2}$ [50]. This is due to the doping of $\mathrm{La}^{3+}$ and $\mathrm{Co}^{2+}$ ions in $\mathrm{TiO}_{2}$, the band gap energy decreased, due to the formation of sub-band by the $\mathrm{La}^{3+}$ and $\mathrm{Co}^{2+}$ ions. Therefore the photocatalytic activity of $\mathrm{TiO}_{2}$ was enhanced by the doping of $\mathrm{La}^{3+}$ and $\mathrm{Co}^{2+}$ into $\mathrm{TiO}_{2}$.

\section{Recyclability of photocatalyst}

The photocatalyst and Methyl Orange mixture was agitated, illuminated with visible light and after desired time, the mixture was centrifuge to remove the photocatalyst. The obtained photocatalyst was washed three times with distilled water and kept in oven for 24 $\mathrm{h}$ at $60^{\circ} \mathrm{C}$ and reused for the photodegradation of methyl orange. The photodegradation of Methyl Orange by the recyclized Photocatalyst are showing in Figure 9. The result shows that the recyclized photocatalyst efficiency is slightly decreased probably due to the loss of some active sites and decrease of collection efficiency of photon [51].

\section{Lowering of electron-hole recombination}

Photoluminescence spectra have been used to examine the mobility of the charge carriers to the surface as well as the recombination process involved by the electron-hole pairs in semiconductor particles. PL emission results from the radiative recombination of excited electrons and holes. In other words, it is a critical necessity of a good photocatalyst to have minimum electron-hole recombination. To study the recombination of charge carriers, PL studies of synthesized materials have been undertaken. PL emission intensity is directly related to recombination of excited electrons and holes. Figure 10 shows the photoluminescence spectra of synthesized photocatalysts. In the PL spectra the intensity of $\mathrm{TiO}_{2}$ is higher than $\mathrm{Co}: \mathrm{La}: \mathrm{TiO}_{2}$ indicating rate of recombination of $\mathrm{e}^{-} \mathrm{h}^{+}$is higher in $\mathrm{TiO}_{2}$ than that of $\mathrm{Co}$ : $\mathrm{La}: \mathrm{TiO}_{2}$. The weak PL intensity of $\mathrm{Co}: \mathrm{La}: \mathrm{TiO}_{2}$ may arise due to the impregnation of $\mathrm{La}^{3+}$ and $\mathrm{Co}^{2+}$ in Titania lattice, which for sub band level in band gap region of $\mathrm{TiO}_{2}$. This delays the electrons- holes recombination process and hence utilized in the redox, reaction leading to improved photocatalytic activity [52].

\section{Hydroxyl radical formation}

As hydroxyl radical performs the key role for the decomposition of the organic pollutants, it is necessary to investigate the amount of hydroxyl radicals produced by each photocatalyst. In this study terephthalic acid (TA) has been used as a probe reagent to evaluate ${ }^{\bullet} \mathrm{OH}$ radical present in the photoreaction pathway. Figures 11 and 12 shows the $\mathrm{PL}$ spectra of $\mathrm{TiO}_{2}$ and Co:La:TiO 2 recorded Methyl Orange solution in presence of $10^{-3} \mathrm{M}$ Terephthalic solution. OH radical attack Terephthalic, forming 2- hydroxyl terephthalic acid $(\mathrm{TAOH})$ which gives a fluorescence signal at $426 \mathrm{~nm}$. The fluorescent intensity is linearly related to the number of hydroxyl radicals formed by the photocatalysts. Higher the generation of hydroxyl radical, more will be yield of TAOH and hence more intense will be the fluorescence peak. The spectra show that the intensity of peak indicating in presence of $\mathrm{Co}: \mathrm{La}: \mathrm{TiO}_{2}$ higher generation of more number of hydroxyl radicals compared to $\mathrm{TiO}_{2}[53]$. 


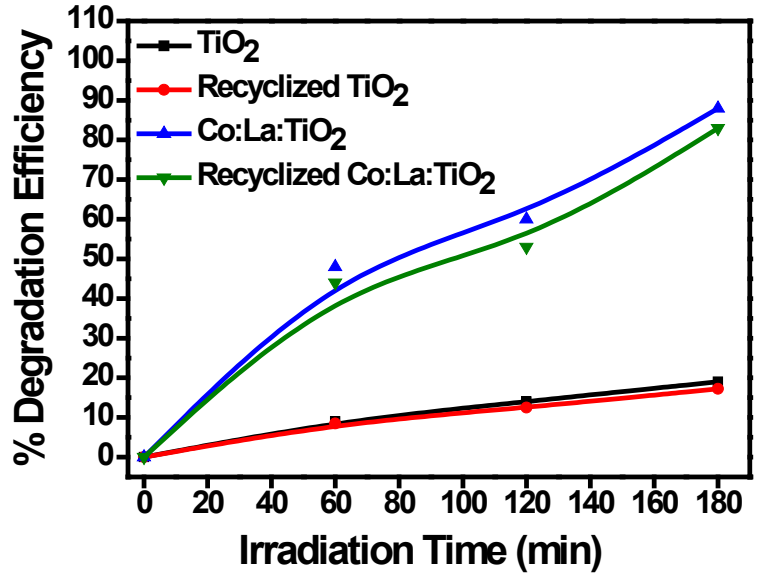

Figure 9: Photodegradation of Methyl Orange by recyclable photocatalyst $\mathrm{TiO}_{2}$ and Co:La:TiO .

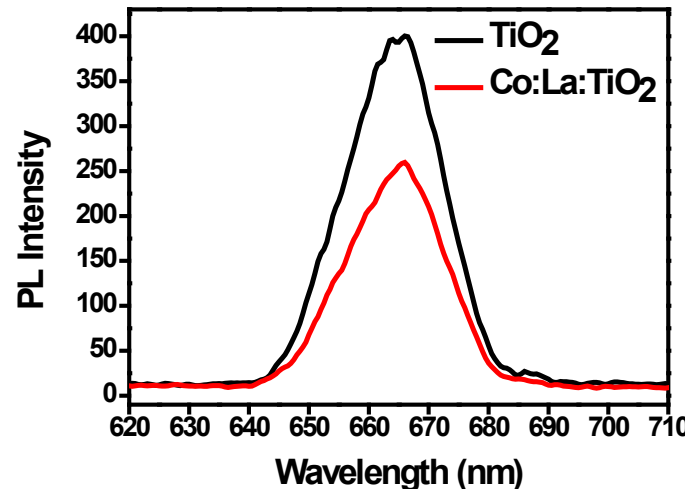

Figure 10: Photolumiscence Spectra of (a) $\mathrm{TiO}_{2}$ (b) Co:La:TiO .

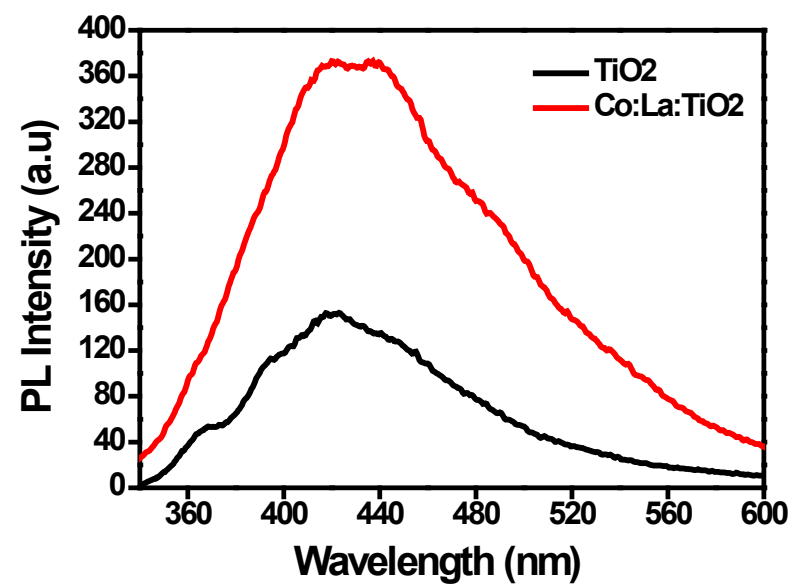

Figure 11: $\mathrm{PL}$ spectra of photocatalysed Methyl Orange solution in presence of terephthalic acid $(0.001 \mathrm{M})(\mathrm{a}) \mathrm{TiO}_{2}$ (b) Co: $\mathrm{La}^{\mathrm{TiO}}{ }_{2}$.

\section{Mechanism of photooxidation process}

$\mathrm{TiO}_{2}+\mathrm{hv} \rightarrow \mathrm{e}_{\mathrm{cb}}+\mathrm{h}^{+}$

Formation of superoxide radical anion

$\mathrm{O}_{2}+\mathrm{e}_{\mathrm{cb}} \rightarrow \mathrm{O}_{2}^{-}$
Neutralization of $\mathrm{OH}^{-}$group into $\mathrm{OH}$ by the hole

$$
\left(\mathrm{H}_{2} \mathrm{O} \Leftrightarrow \mathrm{H}^{+}+\mathrm{OH}^{-}\right)_{\text {ads }}+\mathrm{h}^{+}{ }_{\mathrm{vb}} \rightarrow \cdot \mathrm{OH}+\mathrm{H}^{+}
$$

It is recommended that the hydroxyl radical $\left(\bullet^{\circ} \mathrm{OH}\right)$ and superoxide radical anions $\left(\mathrm{O}_{2}^{-}\right)$are the primary oxidizing species in the photocatalytic oxidation processes [50]. These oxidative reactions would results in the degradation of the pollutants as shown in the following equations $4-5$;

Oxidation of the organic pollutants via successive attack by $\mathrm{OH}$ radicals

$$
\mathrm{R}+{ }^{\bullet} \mathrm{OH} \rightarrow \mathrm{R}+\mathrm{H}_{2} \mathrm{O}
$$

or by direct reaction with holes

$\mathrm{R}+\mathrm{h}^{+} \rightarrow \mathrm{R}^{+} \rightarrow \mathrm{CO}_{2}+\mathrm{H}_{2} \mathrm{O}+\mathrm{NH}_{3}[5]$

\section{Kinetic study}

The pseudo-first-order rate constant $\left(k, \mathrm{~min}^{-1}\right)$ for the photodegradation reaction of Methyl Orange was determined through the following relation where, $k$ can be calculated from the plot of $\ln \left(\mathrm{C}_{\mathrm{o}} /\right.$ $\left.C_{t}\right)$ against time $(t), C_{o}$ and $C_{t}$ denote the initial concentration and reaction concentration, respectively.

$$
\ln \mathrm{C}_{\mathrm{o}} / \mathrm{C}_{\mathrm{t}}=k_{1} t
$$

In addition, the linear feature of plots of $\ln \left(\mathrm{C}_{\mathrm{o}} / \mathrm{C}_{\mathrm{t}}\right)$ versus time (Figure 13) indicates that this photocatalytic degradation reactions follow the pseudo-first-order rate law [54,55]. The rate constant of the photocatalysis at $30^{\circ} \mathrm{C}$ is 0.04260 to $0.0234 \mathrm{~min}^{-1}$. The effect of temperature and concentration are showing in Table 3.

\section{Thermodynamic parameter study}

In this section an attempt has been made to calculate different activation parameters. For this the reaction has been studied at two different temperatures and with the help of observed rate/rate constant, the energy of activation $\left(\Delta \mathrm{E}^{*}\right)$, specific rate constant $\left(\mathrm{k}_{\mathrm{r}}\right)$, entropy of activation $\left(\Delta \mathrm{S}^{*}\right)$, enthalpy of activation $\left(\Delta \mathrm{H}^{*}\right)$, free energy of activation $\left(\Delta G^{*}\right)$ and Arrhenius frequency factor (A) have been computed for different reactions (shown in Table 4) [56].

The activation parameters have been calculated with the help of following equations:

$\Delta \mathrm{E}^{*}=$ value of slope $\times 2.303 \mathrm{R}$

$\log \mathrm{A}=\log \mathrm{kr}\left(\right.$ at $\left.35^{\circ} \mathrm{C}\right)+\mathrm{Ea} / 2.303 \mathrm{RT}$

$\Delta \mathrm{S}^{\star}=2.303 \mathrm{R}(\log \mathrm{A}-13)$

$\Delta \mathrm{G}^{*}=\mathrm{Ea}-\mathrm{T} \Delta \mathrm{S}^{*}$

$\Delta \mathrm{H}^{*}=\Delta \mathrm{G}^{*}+\mathrm{T} \Delta \mathrm{S}^{*}$

The calculated values of various activation parameters for different redox systems are as Table 4 .

\begin{tabular}{|c|c|c|c|c|c|c|c|c|}
\hline & \multicolumn{4}{|c|}{100 ppm } & \multicolumn{4}{|c|}{$50 \mathrm{ppm}$} \\
\hline & \multicolumn{2}{|c|}{$k\left(\min ^{-1}\right) R^{2}$} & \multicolumn{2}{|c|}{$k\left(\min ^{-1}\right) R^{2}$} & \multicolumn{2}{|c|}{$k\left(\min ^{-1}\right) R^{2}$} & \multicolumn{2}{|c|}{$k\left(\min ^{-1}\right) R^{2}$} \\
\hline Sample & \multicolumn{2}{|c|}{$30^{\circ} \mathrm{C}$} & \multicolumn{2}{|c|}{$40^{\circ} \mathrm{C}$} & \multicolumn{2}{|c|}{$30^{\circ} \mathrm{C}$} & \multicolumn{2}{|c|}{$40^{\circ} \mathrm{C}$} \\
\hline $\mathrm{TiO}_{2}$ & 0.006 & 0.969 & 0.011 & 0.999 & 0.005 & 0.955 & 0.009 & 0.986 \\
\hline Co:La: $\mathrm{TiO}_{2}$ & 0.008 & 0.988 & 0.015 & 0.998 & 0.007 & 0.990 & 0.012 & 0.998 \\
\hline
\end{tabular}

\section{Conclusion}

Prepared nanocomposites of $\mathrm{Co}: \mathrm{La}_{\mathrm{TiO}}$ were characterized by

Table 3: The effect of concentration and temperature on rate constant. 
Citation: Azad K, Gajanan P (2017) Photodegradation of Methyl Orange in Aqueous Solution by the Visible Light Active Co:La:TiO ${ }_{2}$ Nanocomposite. Chem Sci J 8: 164. doi: 10.4172/2150-3494.1000164

Page 7 of 9

\begin{tabular}{|c|c|c|c|c|c|}
\hline S. No & Metal Oxide Conditions & $\Delta \mathrm{DE}^{*}$ and $\Delta \mathrm{H}^{*}\left(\mathrm{kjmol}^{-1}\right)$ & $\operatorname{Kr}\left(\min ^{1}\right) \times 10^{-3}$ & $\Delta \mathbf{S}^{*} \times 10^{-3}\left(\mathrm{kjmol}^{-1} \mathrm{~K}^{-1}\right)$ & $\Delta \mathbf{G}^{*}\left(\mathrm{kjmol}^{-1}\right) \times 10^{2}$ \\
\hline \multirow{2}{*}{1} & $\mathrm{TiO}_{2}, 30^{\circ} \mathrm{C}$ & \multirow{2}{*}{24.07} & \multirow{2}{*}{5.26} & \multirow{2}{*}{-69.765} & \multirow{2}{*}{18.23} \\
\hline & $100 \mathrm{ppm}$ & & & & \\
\hline \multirow{2}{*}{2} & $\mathrm{TiO}_{2}, 40^{\circ} \mathrm{C}$ & \multirow{2}{*}{30.23} & \multirow{2}{*}{6.61} & \multirow{2}{*}{-69.463} & \multirow{2}{*}{27.8} \\
\hline & 100 ppm & & & & \\
\hline \multirow{2}{*}{3} & Co:La: $\mathrm{TiO}_{2}, 30^{\circ} \mathrm{C}$ & \multirow{2}{*}{35.33} & \multirow{2}{*}{7.72} & \multirow{2}{*}{-69.154} & \multirow{2}{*}{20.75} \\
\hline & $100 \mathrm{ppm}$ & & & & \\
\hline \multirow{2}{*}{4} & Co:La:TiO, $40^{\circ} \mathrm{C}$ & \multirow{2}{*}{48.23} & \multirow{2}{*}{10.54} & \multirow{2}{*}{-68.535} & \multirow{2}{*}{27.42} \\
\hline & $100 \mathrm{ppm}$ & & & & \\
\hline \multirow{2}{*}{5} & $\mathrm{TiO}_{2}, 30^{\circ} \mathrm{C}$ & \multirow{2}{*}{23.78} & \multirow{2}{*}{5.2} & \multirow{2}{*}{-69.94} & \multirow{2}{*}{20.98} \\
\hline & $50 \mathrm{ppm}$ & & & & \\
\hline \multirow{2}{*}{6} & $\mathrm{TiO}_{2}, 40^{\circ} \mathrm{C}$ & \multirow{2}{*}{34.23} & \multirow{2}{*}{7.48} & \multirow{2}{*}{-69.217} & \multirow{2}{*}{27.69} \\
\hline & $50 \mathrm{ppm}$ & & & & \\
\hline \multirow{2}{*}{7} & Co:La: $\mathrm{TiO}_{2}, 30^{\circ} \mathrm{C}$ & \multirow{2}{*}{33.13} & \multirow{2}{*}{7.24} & \multirow{2}{*}{-69.282} & \multirow{2}{*}{20.78} \\
\hline & $50 \mathrm{ppm}$ & & & & \\
\hline \multirow{2}{*}{8} & Co:La: $\mathrm{TiO}_{2}, 40^{\circ} \mathrm{C}$ & \multirow{2}{*}{50.48} & \multirow{2}{*}{11.03} & -68445 & 2738 \\
\hline & 50 ppm & & & -68.445 & 21.38 \\
\hline
\end{tabular}

Table 4: Thermodynamic parameters for the photocatalytic degradation of Methyl Orange (MB) dye (50 ppm and 100 ppm) and TiO 2 and Co:La:TiO2 (800 mg/L) under Visible light at $30^{\circ} \mathrm{C}$ and $40^{\circ} \mathrm{C}$ temperature.

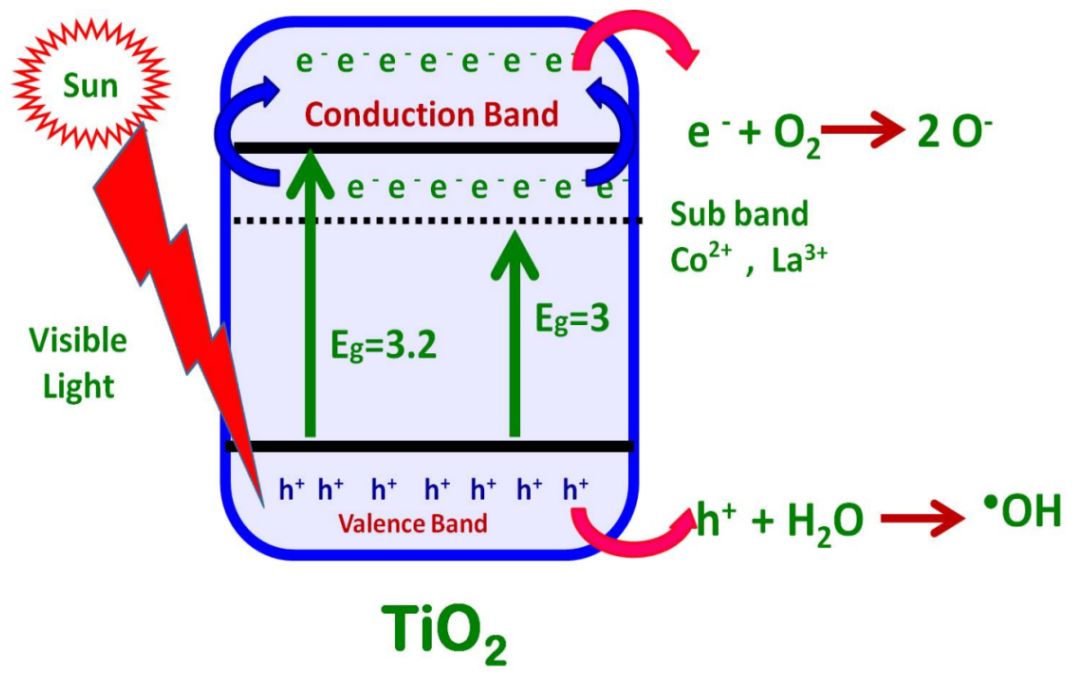

Figure 12: Mechanism of free radical formation in the photocatalysis.
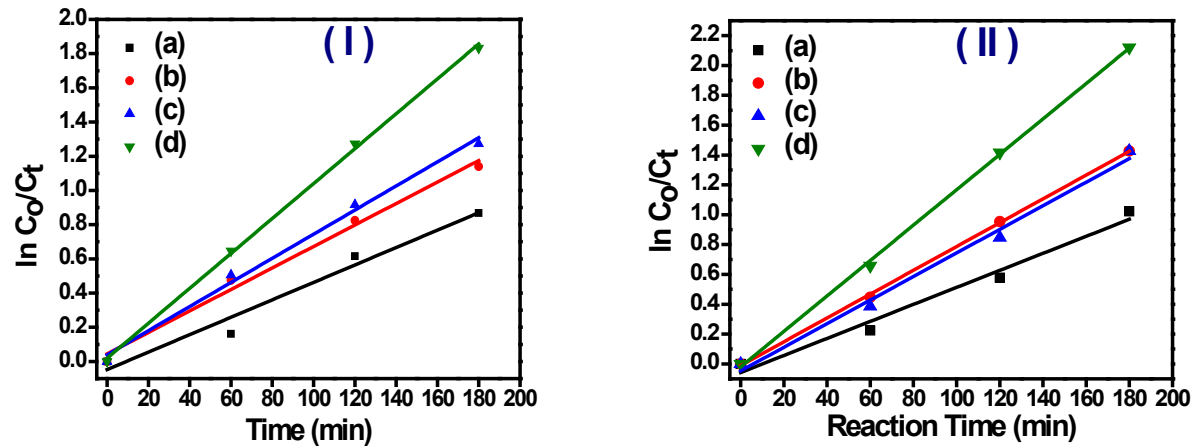

Figure 13: The straight line relationship between the $\ln \left(\mathrm{C}_{\mathrm{o}} / \mathrm{C}_{\mathrm{t}}\right)$ and irradiation time (a) $\mathrm{TiO}_{2}$ at $30^{\circ} \mathrm{C} \mathrm{(b)} \mathrm{TiO}_{2}$ at $40^{\circ} \mathrm{C} \mathrm{(c)} \mathrm{Co}^{\circ} \mathrm{La}: \mathrm{TiO}_{2}$ at $30^{\circ} \mathrm{C}(\mathrm{d}) \mathrm{Co}^{\circ} \mathrm{La}: \mathrm{TiO}_{2}$ at $40^{\circ} \mathrm{C}$ for methyl orange (I) 50 ppm (II) 100 ppm.

X-Ray Diffractometer, SEM, TEM, UV- Vis, FT-IR, Band gap energy and BET. The $\mathrm{TiO}_{2}$ and Co:La:TiO 2 were used as photocatalyst for the degradation of Methyl Orange. The particle size was estimated by the Scherrer's calculation and found 68 and $32 \mathrm{~nm}$ for $\mathrm{TiO}_{2}$ and Co:La:TiO respectively. The surface area of the photocatalysts were found 37.52 and $106.68 \mathrm{~m}^{2} / \mathrm{g}$ for $\mathrm{TiO}_{2}$ and $\mathrm{Co}: \mathrm{La} \cdot \mathrm{TiO}_{2}$ respectively. The band gap energy of $\mathrm{TiO}_{2}$ and $\mathrm{Co}: \mathrm{La}: \mathrm{TiO}_{2}$ were 3.2 and $3.0 \mathrm{eV}$. The photodegradation of Methyl Orange has been found $98.9 \%$ at $25 \mathrm{ppm}$ concentration of dye, 
Citation: Azad K, Gajanan P (2017) Photodegradation of Methyl Orange in Aqueous Solution by the Visible Light Active Co:La:TiO ${ }_{2}$ Nanocomposite. Chem Sci J 8: 164. doi: 10.4172/2150-3494.1000164

Page 8 of 9

$88 \%$ at $5 \mathrm{pH}, 96 \%$ at $800 \mathrm{mg} / \mathrm{L}$ amount of photocatalyst and $98.5 \%$ at 180 min illumination of visible light in presence of $\mathrm{Co}: \mathrm{La}: \mathrm{TiO}_{2}$ whereas in case of $\mathrm{TiO}_{2}$ about $20 \%$ photodegradation was observed. Hence the prepared Co:La:TiO nanocomposite is the efficient and superior photocatalyst than the neat $\mathrm{TiO}_{2}$. The photodegradation was following the first order kinetics.

\section{Acknowledgements}

We thanks for financial assistance to UGC, Government of India is acknowledged. The authors also acknowledge the support provided by the Babasaheb Bhimrao Ambedkar University, Lucknow, India.

\section{References}

1. Mahmoud MA, Poncheri A, Badr Y (2009) Photocatalytic degradation of Methyl Orange dye. South African J Science 105: 299-303.

2. Sauer T, Neto GC, Jose HJ, Moreira RF (2002) Kinetics of photocatalytic degradation of reactive dyes in a $\mathrm{TiO}_{2}$ slurry reactor. Journal of Photochemistry and Photobiology A: Chemistry 149: 147-154.

3. Kavitha SK, Palanisamy PN (2011) Photocatalytic and sonophotocatalytic degradation of reactive red 120 using dye sensitized $\mathrm{TiO}_{2}$ under visible light. International Journal of Civil and Environmental Engineering 3: 1-6.

4. Lee H, Park YK, Kim SJ, Kim BH, Jung SC (2015) Titanium dioxide modification with cobalt oxide nanoparticles for photocatalysis. Journal of Industrial and Engineering Chemistry 32: 259-263.

5. Makwana MN, Christopher JT, Robert IG, McMillan PF (2016) Pilot plant scale continuous hydrothemal synthesis of nano- titania; effect of size on photocatalytic activity. Materials Science in Semiconductor Processing 42: 131-137

6. Liu S, Jaffrezic N, Guillard C (2008) Size effects in liquid-phase photo-oxidation of phenol using nanometer-sized $\mathrm{TiO}_{2}$ catalysts. Appl Surf Sci 255: 2704-2709.

7. Gnanaprakasam A, Sivakumar VM, Sivayogavalli PL, Murugan MT (2015) Characterization of $\mathrm{TiO}_{2}$ and $\mathrm{ZnO}$ nanoparticles and their applications in photocatalytic degradation of azodyes. Ecotoxicol Environ Saf 121: 121-125

8. Wang DN, Tafen JP (2009) Origin of photocatalytic activity of Nitrogen-doped TiO2 nanobelts. J Am Chem Soc 131: 12290-12297.

9. Hariprasad N, Anju SG, Yesodharan EP, Suguna Y (2013) Sunlight induced removal of Rhodamine B fromwater through semiconductor photocatalysis: effects of adsorption, reaction conditions and additives. Research Journal of Material Science 1: 19-17.

10. Zhang Z, Brown Z, Goodall JBM, Weng X, Thompson K, et al. (2009) Direct continuous hydrothermal synthesis of high surface area nanosized titania. $J$ Alloys and Compounds 476: 451-456

11. Kumar SG, Devi LG (2011) Review on Modified $\mathrm{TiO}_{2}$ Photocatalysis under UV Visible Light: Selected Results and Related Mechanisms on Interfacial Charge Carrier Transfer Dynamics. J Phys Chem A 115: 13211-13241

12. Jia H, Zheng Z, Zhao H, Zhang L, Zou Z (2009) Non aqueous sol-gel synthesis and growth mechanism of single crystalline $\mathrm{TiO}_{2}$ nanorods with high photocatalytic activity. Materials Research Bulletin 44: 1312-1316.

13. Silva CG, Wang W, Faria JL (2006) Photocatalytic and photochemical degradation of mono-, di- and tri-azo dyes in aqueous solution under UV irradiation. J Photochemistry and Photobiology A: Chemistry 181: 314-324.

14. Epling AG, Lin C (2002) Photoassisted bleaching of dyes utilizing $\mathrm{TiO}_{2}$ and visible light. Chemosphere 46: 561-570

15. Sökmen M, Özkan A (2002) Decolourising textile wastewater with modified Titania: the effects of inorganic anions on the photocatalysis. Journal of Photochemistry and Photobiology A: Chemistry 147: 77-81.

16. Badr Y, Abd El-Wahed MG, Mahmoud MA (2008) Photocatalytic degradation of Methyl Orange dye by silica nanoparticles. J Hazardous Materials 154: 245-253.

17. Akyol A, Bayramoglu M (2008) The degradation of an azo dye in a batch slurry photocatalytic reactor. Chemical Engineering and Processing: Process Intensification 47: 2150-2156.

18. Gupta AK, Pal A, Sahoo C (2006) Photocatalytic degradation of a mixture of Crystal Violet (Basic Violet 3) and Methyl Orange dye in aqueous suspensions using $\mathrm{Ag}^{+}$doped $\mathrm{TiO}_{2}$. Dyes and Pigments 69: 224-232.
19. Zakarya SA, Kassim A, Lim HN, Anwar NS (2010) Synthesis of titanium dioxide microstructures via sucrose ester microemulsion-mediated hydrothermal method. Sains Malaysiana 39: 975-979.

20. Rohit B, Madhulika S, Bahadur D (2013) Visible light-driven nanocomposites $\left(\mathrm{BiVO}_{4} / \mathrm{CuCr}_{2} \mathrm{O}_{4}\right)$ for efficient degradation of organic dye. Dalton Trans 42 : 6736-6744.

21. Selvam K, Muruganandham M, Muthuvel I, Swaminathan M (2007) The influence of inorganic oxidants and metal ions on semiconductor sensitized photodegradation of 4-fluorophenol. J Chem Eng 128: 51-57.

22. Ufana R, Ashraf SM (2011) Semi-conducting poly (1-naphthylamine) nanotubes: a pH independent adsorbent of sulphonate dyes. Chem Eng J 174: 546-555.

23. Zhao D, Sheng G, Chen C, Wang X (2012) Enhanced photocatalytic degradation in methylene Orange under visible irradiation on grapheme@ $\mathrm{TiO}_{2}$ dyade structure. Appl Catal B: Environ 111: 303-308.

24. Tanaka K, Padermpole K, Hisanaga T (2000) Photocatalytic degradation of commercial azo dyes. Wat Res 34: 327-333.

25. Zhu Y, Xu S, Yi D (2010) Photocatalytic degradation of methyl orange using polythiophene/ titanium dioxide composites. Reactive \& Functional Polymers 70: 282-287.

26. Tang WZ, An H (1995) UV/TiO 2 photocatalytic oxidation of commercial dyes in aqueous solution. Chemosphere 31: 4171-4183.

27. Wang X, Chen G, Zhang J (2013) Synthesis and Characterization of Novel $\mathrm{Cu}_{2} \mathrm{O} / \mathrm{PANI}$ Composite Photocatalysts with Enhanced Photocatalytic Activity and Stability. Catal Commun 31: 57-61.

28. Cullity BD, Stock SR (2001) Elements of X-Ray Diffraction, Third Edition, and New Jersey: Prentice-Hall, Newyork.

29. Zhao J, Chen C, Ma W (2005) Photocatalytic degradation of organic pollutants under visible light irradiation. Topics in Catalysis. 35: 269-278.

30. Wang DS, Zhang J, Luo QZ, Li XY, Duan YD (2009) Characterization and photocatalytic activity of poly(3-hexylthiophene)-modifiedTiO $\mathrm{Tor}_{2}$ degradation of methyl orange under visible light. J Hazard Mater 169: 546-550.

31. Salem MA, Al-Ghonemiy AF, Zaki AB (2009) Photocatalytic degradation of Allura red and Quinoline yellow with Polyaniline/ $\mathrm{TiO}_{2}$ Nanocomposite. Appl Catal B: Environ 91: 59-66

32. Reddy KM, Manorama SV, Reddy AR (2002) Bandgap studies on anatase titanium dioxide nanoparticles. Materials Chemistry and Physics 78: 239-245.

33. Langmuir I (1918) The adsorption of gases on plane surfaces of glass, mica and platinum. J Am Chem Soc 40: 1361-1403.

34. Nomanbhay SM, Palanisamy K (2004) Removal of heavy metals from industrial wastewater using chitosan coated oil palm shell charcoal. Electron J Biotechnol 8: 43-53.

35. Mahmood T, Din SU, Naeem A, Mustafa S, Waseem M, et al. (2012) Adsorption of arsenate from aqueous solution on binary mixed oxide of iron and silicon. Chem Eng J 192: 90-98.

36. Gong R, Zhu S, Zhang D, Chen J, Ni S, et al. (2008) Adsorption behavior of cationic dyes on citric acid esterifying wheat straw: kinetic and thermodynamic profile. Desalination 230: 220-228.

37. Goel NK, Kumar V, Misra N, Varshney L (2015) Cellulose based cationic adsorbent fabricated via radiation grafting process for treatment of dyes waste water. Carbohydrate Polymers 132: 444-451.

38. Wijannarong S, Aroonsrimorakot S, Thavipoke P, Kumsopa C, Sangjan S (2013) Removal of Reactive Dyes from Textile Dyeing Industrial Effluent by Ozonation Process. APCBEE Procedia 5: 279-282.

39. Gu L, Wang J, Qi R, Wang X, Xu P, et al. (2012) A novel incorporating style of polyaniline/TiO2 composites as effective visible Photocatalysts. J Molec Catal A: Chem. 357: 19-25.

40. Vinodopal K, Wynkoop DE, Kamate PV (1996) Environmental photochemistry on semiconductor surfaces: photosensitized degradation of a textile azo dye, Acid Orange 7, on TiO2 particles using visible light. Environ Sci Technol 30: 1660.

41. Saquib M, Muneer M (2003) TiO2 photocatalytic degradation of a tripheny methane dye (gentian violet), in aqueous suspensions. Dyes and Pigments 56: 37. 
Citation: Azad K, Gajanan P (2017) Photodegradation of Methyl Orange in Aqueous Solution by the Visible Light Active Co:La:TiO ${ }_{2}$ Nanocomposite. Chem Sci J 8: 164. doi: 10.4172/2150-3494.1000164

42. Tanaka K, Padermpole K, Hisanaga T (2000) Photocatalytic degradation of commercial azo dyes. Water Res 34: 327.

43. Hu C, Yu JC, Hao Z, Wong PK (2003) Effect of acidity and inorganic ions on the photocatalytic degradation of different azo dyes. Applied catalysis B: Environmental 46: 35.

44. Konstantinou IK, Albanis TA (2004) TiO2 assisted photocatalytic degradation of azo dyes in aqueous solution:kinetic and mechanistic investigations. Applied catalysis B: Environmental 49: 1-14

45. Wang B, Wu F, Li P, Deng N (2007) UV-light induced photodegradation of bisphenol in water: kinetics and influencing factors. React kinet catal Lett 92: 3-9.

46. Neamtu M, Siminiceanu I, Yediber A, Kettrup A (2002) Kinetics of decolorization and mineralization of reactive azo dyes in aqueous solution by $\mathrm{UV} / \mathrm{H} 2 \mathrm{O} 2$ oxidation. Dyes and Pigments 53: 93-99.

47. Baran E, Yazici B (2016) Effect of different nano-structured Ag doped TiO2-NTs fabricated by electrodeposition on the electrocatalytic hydrogen production. International Journal of Hydrogen Energy 41: 2498-2511.

48. Sun Q, Xu Y (2009) Sensitization of TiO2 with Aluminum Phthalocyanine: Factors Influencing the Efficiency for Chlorophenol Degradation in Water under Visible Light. J Phys Chem C 113: 12387-12394.

49. Wang S (2008) A comparative study of Fenton and Fenton-like reaction kinetics in decolourization of wastewater. Dyes and Pigments 76: 714-720.
50. Guettaı N, Amar HA (2005) Photocatalytic oxidation of methyl orange in presence of titanium dioxide in aqueous suspension. Part II: Kinetics study. Desalination 185: 439-448.

51. Chen D, Ray AK (1999) Photocatalytic kinetics of phenol and its derivatives over UV irradiated $\mathrm{TiO}_{2}$. Appl Catal B: Environ 23: 143-157.

52. Gupta VK, Jain R, Siddiqui MN, Saleh TA, Agarwal S, et al. (2010) Equilibrium and thermodynamic studies on the adsorption of the dye Rhodamine-B onto mustard cake and activated carbon. J Chem Eng Data 55: 5225-5229.

53. Pradhan GK, Padhi D, Parida K (2013) Fabrication of $\alpha$-Fe2O3 Nanorod/RGO composite: A novel hybrid photocatalyst for phenol degradation. Appl Mater Interfaces 5: 9101-9110

54. Vinuth M, Naik HSB, Vinoda BM, Pradeepa SM, Arun KG, et al. (2016) Rapid Removal of Hazardous Rose Bengal Dye Using Fe(III)-Montmorillonite as an Effective Adsorbent in Aqueous Solution. J Environ Anal Toxicol 6: 355.

55. Chen D, Ray AK (1998) Photodegradation kinetics of 4-nitrophenol in $\mathrm{TiO}_{2}$ suspension. Water research 32: 3223-3234.

56. Galvan D, Orives JR, Coppo RL, Silva ET, Angilelli KG, et al. (2013) Determination of the Kinetics and Thermodynamics Parameters of Biodiese Oxidation Reaction Obtained from an Optimized Mixture of Vegetable Oil and Animal Fat. Energy Fuels 27: 6866-6871. 